\title{
INFÂNCIA ROUBADA: MEMÓRIAS E POÉTICAS DA RESISTÊNCIA NO CINEMA LATINO-AMERICANO
}

\author{
STOLEN CHILDHOOD: MEMORIES AND \\ POETRY OF RESISTANCE IN LATIN AMERICAN CINEMA
}

\author{
SILVA, Adriana A. \\ silvadida07@gmail.com \\ Rede Municipal de Ensino de Florianópolis / SC
}

\begin{abstract}
Resumo A partir de uma tese de doutorado, o presente texto apresenta reflexões sobre a infância pelas lentes do cinema, com foco nas ditaduras militares latino americanas. A metodologia utilizada articulou a estética da infância no cinema com o conceito de rememoração de Walter Benjamim, analisando entre outros, os filmes: "A História Oficial" e Infância Clandestina (Argentina), Machuca (Chile), O ano que meus pais saíram de férias (Brasil). Como "resultados" da pesquisa evidenciamos emergentes poéticas das resistências nas analisadas narrativas cinematográficas latino-americanas, destacando a cineasta argentina Albertina Carri, com seus filmes Los Rubios (2003) e La Rabia (2012).

Palavras-chave: Cinema. Infâncias. Memórias. Poéticas. Resistências.
\end{abstract}

Abstract From the doctoral thesis, this article presents reflections about childhood by cinema's lenses, focusing on Latin American military dictatorships. The methodology used articulated childhood's aesthetics in cinema with the concept of remembrance in Walter Benjamin, analyzing among other films: The Official Story and Clandestine Childhood (Argentina), Machuca (Chile), The Year that my parents went on vacation (Brazil). As "results" of research we evidenced poetry from the resistances analyzed in Latin American cinematic's narrative, highlighting the Argentine filmmaker Albertina Carri, with her films Los Rubios (2003) and La Rabia (2012).

Keywords: Cinema. Childhoods. Memories. Poetry. Resistances.

\section{ATRÁS DOS RASTROS DA MEMÓRIA: CINEMA, INFÂNCIA E EDUCAÇÃO}

O presente texto apresenta reflexões de uma tese de doutorado e destaca um processo de pesquisa e criação desencadeado no final dos anos 1990. Conclui o Mestrado em Multimeios (cinema e vídeo) no Instituto de Artes da Unicamp em 2008, dez anos após minha entrada na mesma universidade no curso de Pedagogia, tendo como atividade universitária inicial uma visita aos arquivos do AEL (Arquivo Edgard Leueronth), encontrando a documentação para o início do processo de Anistia dos meus pais (ambos ex-militantes do Partido Comunista), nos arquivos do Brasil nunca Mais. Em 2009 ingressei no Doutorado em Educação com um projeto de pesquisa sobre a Estética da Infância no Cinema. 
Contagiada pela memória desencadeada no mestrado ${ }^{1}$, selecionei filmes recentes com protagonistas crianças em contextos de luta política contra as ditaduras militares na América Latina e na Europa. Infâncias roubadas nas ditaduras militares que foram rememoradas no cinema, entre outros, analisei os filmes $A$ História Oficial, Infância Clandestina (Argentina, 1985 e 2012, respectivamente), Machuca (Chile, 2004), e O ano em que meus pais saíram de férias (Brasil, 2006), buscando através de suas imagens e sons ver, ouvir as crianças narradoras que vêm representando, construindo e desconstruindo infâncias protagonistas, em contextos de luta política.

Nesta perspectiva, tive a intencionalidade de entrelaçar: a infância no cinema, a criança narradora e/ou o processo de rememoração dos cineastas em produções que não dissociam arte da política, e colocam no cenário social contemporâneo os bebês e as crianças como protagonistas das lutas e dos conflitos sociais.

Atrás dos rastros da memória, através da arte, tendo o cinema como referência, busquei olhar a complexidade destas infâncias "clandestinas" na relação com movimentos sociais dos direitos humanos, na intencionalidade de contribuir na construção de outros olhares sensíveis e críticos para as crianças. E, neste sentido, também contribuir no constante desafio da luta por uma educação emancipadora, que visa às emergentes transformações da sociedade em suas utopias revolucionárias.

\section{A INFÂNCIA VAI AO CINEMA: ARTE E POLÍTICA NA CONSTRUÇÃO DA MEMÓRIA}

O filme $O$ ano em que meus pais saíram de férias, realizado em 2005, pelo cineasta Cao Hamburguer, é o primeiro filme brasileiro a apresentar a ditadura militar a partir de uma perspectiva infantil, ou sob a ótica da infância. Segundo entrevistas, o diretor resgata neste filme, de alguma forma, a memória de sua própria infância, rememorada, reinventada e ressignificada.

Mauro é o pequeno protagonista do filme, deixa com os pais Belo Horizonte,

\footnotetext{
${ }^{1}$ Fiz o mestrado em Multimeios (cinema e vídeo) no Instituto de Artes da Unicamp, sobre processos criativos, literatura e audiovisual.
} 
tendo como destino a cidade de São Paulo, onde será deixado com o avô paterno, que trabalha numa barbearia, porém há toda uma belíssima sequência de desencontro com o avô - que sempre é pontual, com o pai que está sempre atrasado e do neto, que fica a deriva na narrativa (pois o avô morre no início do filme), o menino é deixado pelos pais na porta do prédio do avô. Mauro acaba abrigado por um vizinho, sendo acolhido pela comunidade judaica do bairro.

Muito mais intenso do que a violência física há uma violência simbólica em toda a narrativa, velada, silenciosa e poderosa, que é a da iminência constante da repressão, do medo, da liberdade negada.

Marcelo Ridenti, no livro O fantasma da Revolução Brasileira (sua tese de doutorado em Sociologia na USP, defendida em 1989), em um inspirador Prefácio Pessoal e Político (p. 17-25), também busca referências cinematográficas para suscitar estes anos de chumbo,

\begin{abstract}
Esteve em cartaz em São Paulo, em 1983, o filme de Marguarethe Von Trotta Os anos de chumbo ${ }^{2}$, baseado na vida de uma terrorista de esquerda da Alemanha Ocidental, na década de 1970, que apareceu morta numa prisão de alta segurança; quase certo assassinada pela policia como represália a uma serie de atentados. Na fita, essa militante tinha um filho pequeno, criado pelo pai, devido a vida clandestina da mãe antes de ser presa. O filme tem inicio quando o pai deixa o garoto com a irmã de sua mulher por uns dias, com um pretexto qualquer, para não mais voltar: ele comete suicídio.(...) Na última cena, o garoto pega uma foto da mãe afixada na parede do escritório e a rasga. A tia, entre consternada e indignada, repreende o menino, dizendo-lhe que sua mãe fez o que pôde por ele, deu a vida por uma causa, ou algo assim. Ele não desistia e respondia duramente, dizendo à tia que começasse a contar em detalhes o que sua mãe fizera por ele. No desfecho da história, coloca-se esse questionamento implacável do garoto (RIDENTI, 2010, p. 21).
\end{abstract}

Ridenti busca, através de Os anos de chumbo e San Michele aveva um gallo (1982) - produção italiana dos irmãos Taviani -, ilustrar através dos argumentos destes filmes as questões geracionais que envolvem o fato histórico dos anos de chumbo e a da luta armada, assim como a repressão e a alienação das gerações posteriores, tanto do ponto de vista da ignorância histórica como da incompreensão

2 Margarethe Von Trotta (1942) é uma importante cineasta alemã, pouco conhecida no Brasil, teve uma mostra retrospectiva de sua obra em 2006 no CCBB, em meio as comemorações do 8 de março. Prestigiada venceu o leão de ouro no Festival de Veneza com o filme Anos de Chumbo, 1981. Seu tema: mulheres e política, entre outros realizou Rosa Luxemburgo (1986) e Hannah Arendt (2012). 
política, uma vez que trata de um passado nefasto e sombrio ${ }^{3}$.

Segundo ele, há uma grande parte da geração posterior ao golpe militar, as crianças daquele período, os jovens estudantes universitários como ele, identificados com o filho da terrorista alemã: "abandonado, sofrido e despolitizado [...] O menino queria saber das condições que o geraram como individuo e como ser social de um mundo brutalizante, em que o humano está submetido à lógica das coisas" (RIDENTI, 2010, p. 22).

Assim como Mauro? Na minha interpretação, não. A opção de Cao Hamburger, e enfatizada nos depoimentos de atores e membros da equipe do filme, foi de focar na(s) resistência(s) da(s) criança(s), buscando uma estética da infância, com foco no processo cotidiano de ressignificar as condições dadas e recriar possibilidades de criação das culturas infantis, apesar das brutalizações do mundo "adulto" a espreita, elas jogam, brincam, brigam, reinventam o mundo.

É notória a experiência do diretor com o universo infantil, ele tem uma extensa carreira com cinema de animação, televisão, em especial os trabalhos com 0 Castelo Rá tim bum ${ }^{4}$, que também virou longa para o cinema.

Figura 1. Sequências do filme $O$ ano que meus pais saíram de férias, referenciando o contexto dos anos de chumbo.

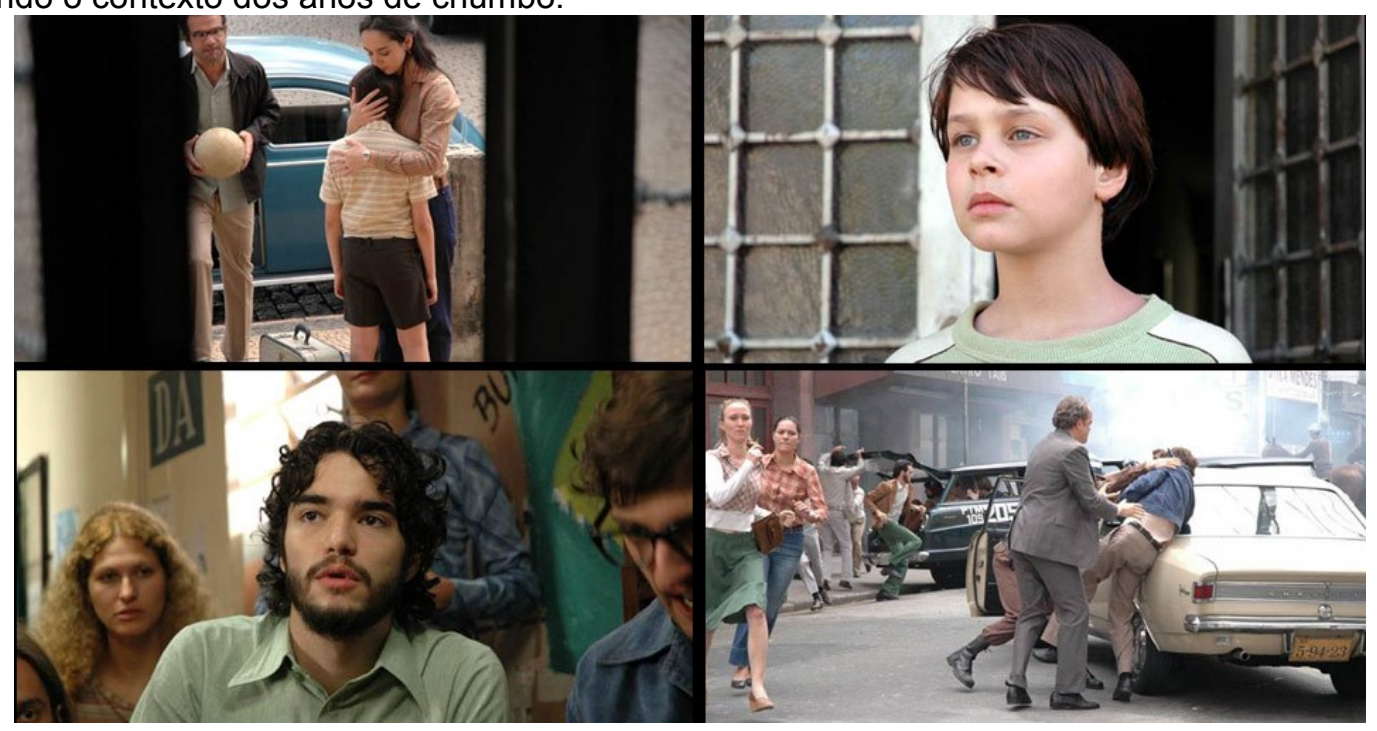

Fonte: Imagens da Tese de Doutorado: A estética da infância no cinema: poéticas e culturas infantis.

3 Cabe destacar neste movimento de resgate da memória da infância na ditadura brasileira o documentário "15 filhos" (1996) de Maria Oliveira e Marta Nehring, que traz depoimentos de 'crianças' (no filme realizado na década de 90, são jovens) presas na ditadura militar.

${ }^{4}$ O castelo Rá-Tim-Bum! É uma série da TV Cultura que completou recentemente 18 anos (foi criado em 1994), dirigida pelo Cao Hamburguer que o adaptou para o cinema em 1999. É um marco e um clássico da programação para as crianças na TV brasileira. 
SILVA, A. A. FE UNICAMP: Campinas, São Paulo. 2014, p. 46.

Outras referências cinematográficas para problematizar os rastros da memória, educação, infância e cinema foram os filmes argentinos $A$ Historia Oficial (1985) e Infância Clandestina (2012) duas produções cinematográficas que se conectam no tempo e espaço, de maneiras distintas com o enfoque sobre a questão da infância na ditadura militar. Porém, ambos são exemplares para a reflexão sobre a estética da infância no cinema, tendo como pressuposto teórico metodológico, compreender os filmes como "documentos" plenos de uma emergência histórica.

Fredric Jameson em As marcas do visível (1995, p. 1) na sua introdução defende que,

[...] a única maneira de pensar o visual, de inteirar-se de uma situação em que a visualidade é uma tendência cada vez mais abrangente, generalizada e difundida é compreender sua emergência histórica. Outros tipos de pensamento precisam substituir o ato de ver por outra coisa; apenas a história, entretanto, pode imitar o aprofundamento ou a dissolução do olhar.

Considerando o ato de ver, nesta perspectiva histórica repleta de contradições, como olhamos estes filmes? Percebemos os movimentos de aproximação e recuos ao retrataram a história recente de seu país? E, como a infância é protagonista destas narrativas, para além das crianças concretas e da experiência física que estes filmes possibilitam?

A Historia Oficial dirigida por Luis Puenzo, lançado em 1985, foi um filme marco do cinema político contemporâneo na America Latina. Sua emergência histórica foi evidenciada pela repercussão nacional e internacional, ganhando o Oscar de melhor filme estrangeiro.

A emergência histórica de $A$ história Oficial é reacendida ${ }^{5} 27$ anos depois, com a produção do filme Infância Clandestina (2012), um filme atual que o tem como referência fundamental, porém que busca outras formas estéticas e políticas de fazer um filme histórico. A minha leitura, vai de encontro com a perspectiva adotada no filme $O$ ano em que meus pais saíram de férias, apresentando o ponto de vista da criança como sujeito histórico e busca uma estética que dê forma a esta

\footnotetext{
${ }^{5}$ Outros filmes nos últimos anos vêm trazendo de formas distintas esta temática, em especial destaco as produções argentinas: Kamchatka (2002) de Marcelo Pineyro e O dia em que eu não nasci (2010) de Florian Micoud Cossen, uma produção Alemanha/Argentina.
} 
intencionalidade política.

O primeiro longa metragem do diretor argentino Benjamim Ávila, foi produzido por Luis Puenzo (diretor de A História Oficial) que também foi indicado ao Oscar de melhor filme estrangeiro pela Argentina. Teve coprodução brasileira e vai ao encontro com as produções artísticas de crianças de ontem, que buscam retratar, às suas maneiras, os dramas vividos no passado. Segundo declarações de seu diretor, trata-se de uma homenagem às pessoas que lutaram contra a ditadura militar em seu país. Tem em seu protagonista - Juan-Ernesto (um garoto de 11 anos) - o alter ego do diretor que viveu a infância na clandestinidade com seus pais, militantes da organização Montoneros.

Figura 2. Imagens do filme A História Oficial: com ênfase ao movimento das mães da Plaza di Mayo.

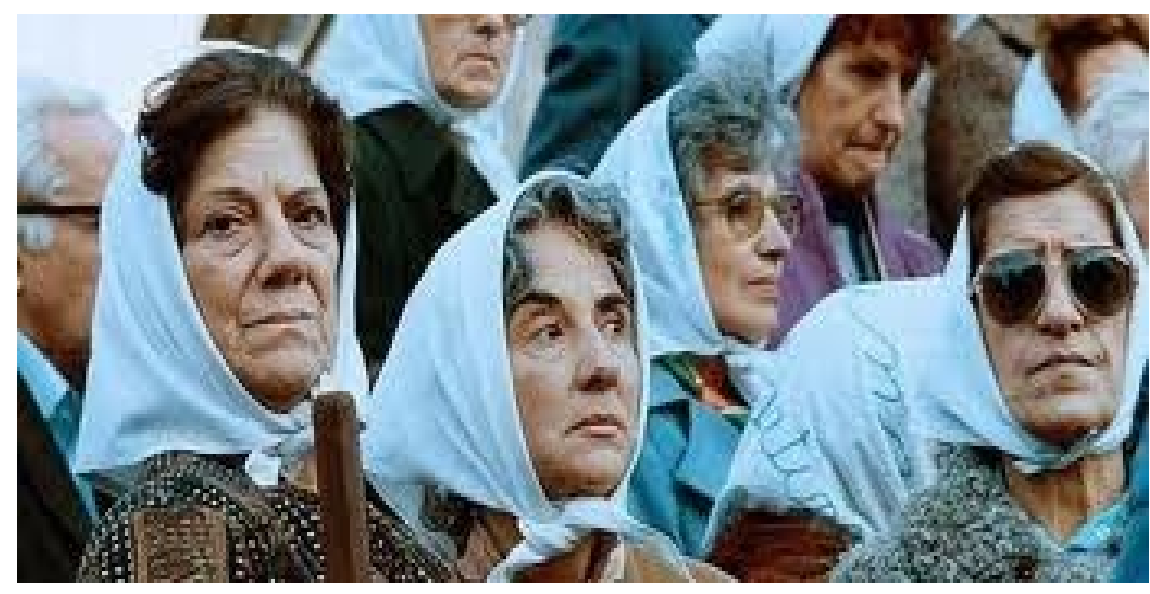

Fonte: Imagens da Tese de Doutorado: A estética da infância no cinema: poéticas e culturas infantis. SILVA, A. A. FE UNICAMP: Campinas, São Paulo. 2014, p. 51.

Figura 3. Imagens da mãe do protagonista no filme Infância Clandestina. O filme é dedicado à mãe do diretor.
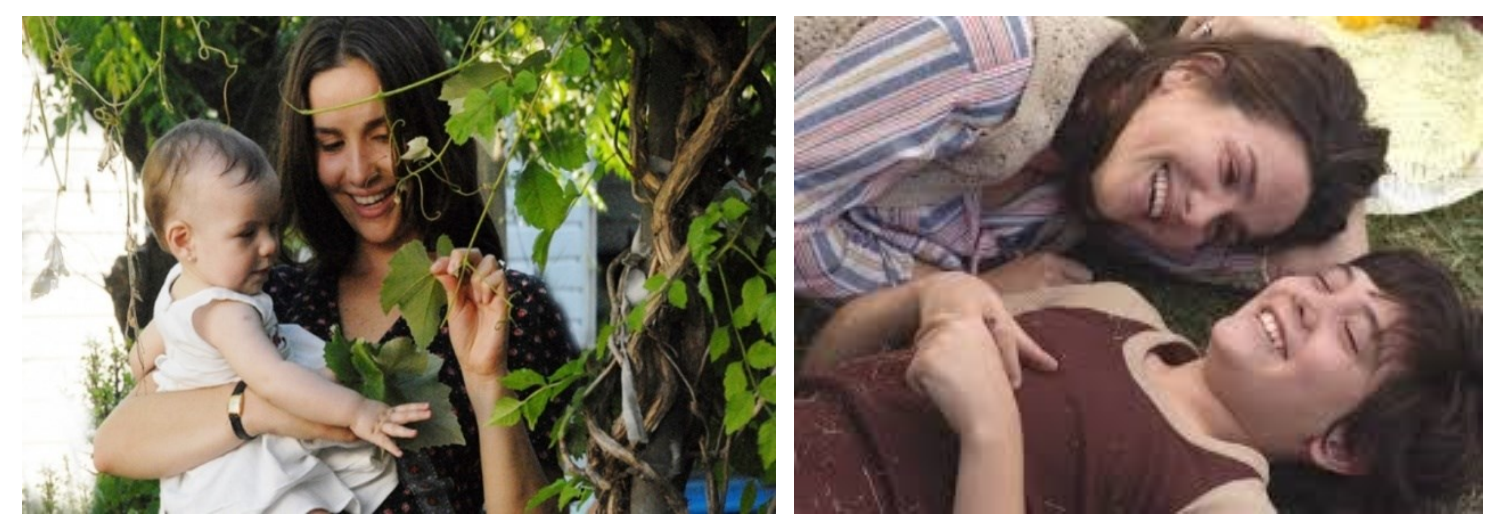
Fonte: Imagens da Tese de Doutorado: A estética da infância no cinema: poéticas e culturas infantis. SILVA, A. A. FE UNICAMP: Campinas, São Paulo. 2014, p. 54.

\section{ESTÉTICA E POÉTICAS DA INFÂNCIA NO CINEMA}

Considerando as relações entre estética como a partilha do sensível (Rancière, 2005), diretamente atrelada à política, minha proposição foi a de relacionar a dimensão da linguagem pedagógica das coisas (Pasolini,1990) com poéticas da infância, através das experiências de rememoração de filmes que trazem as crianças como protagonistas em momentos históricos recentes da América Latina.

Outras referências fundamentais do processo foram os filmes $A$ culpa é do Fidel (2006) uma produção francesa de Julie Gravas e Machuca (2004) produção chilena/espanhola de Andres Wood, filmes de dois jovens diretores, que trazem em suas narrativas audiovisuais memórias e processos de rememoração de suas próprias vidas. Os dois filmes têm, em comum, a abordagem histórica protagonizada por crianças nos anos 1970, trazendo o ponto de vista da infância para também narrar os episódios envolvendo a esquerda européia e suas relações com a America Latina, o golpe militar no Chile e suas relações de classe com os personagens infantis diretamente envolvidos.

Figura 4. Imagens dos cartazes de divulgação dos filmes: crianças protagonistas de dramas políticos. 

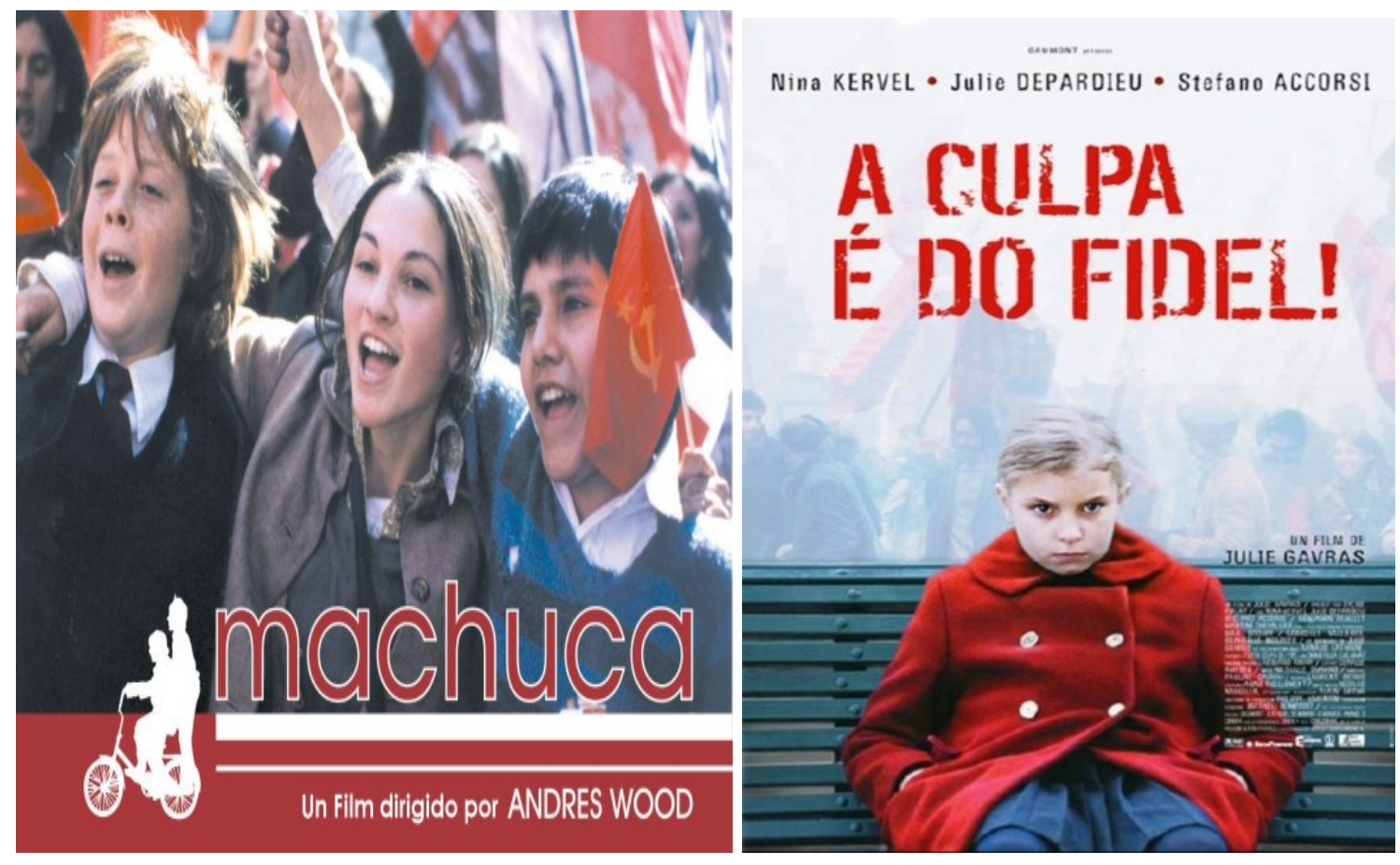

Fonte: Imagens da Tese de Doutorado: A estética da infância no cinema: poéticas e culturas infantis. SILVA, A. A. FE UNICAMP: Campinas, São Paulo. 2014, p. 91.

A culpa é do Fidel é o drama cômico de Anna, uma personagem de 9 anos que vive em Paris, de família burguesa, tem seu mundo definido pelas suas condições e determinações de classe que ela aceita, reproduz e aparentemente vive em tranqüilidade. Isto fica evidente na primeira sequência do filme que a apresenta, numa festa de casamento de uma prima da mãe. O tempo é meados dos anos 1970. Anna tem um irmão e os pais como coadjuvantes de sua história, além da babá do início da narrativa, uma exilada cubana que odeia Fidel Castro, sendo ela a referência irônica do título do filme. Porém, este mundo harmoniosamente burguês é ameaçado e gradativamente se desmorona a partir das escolhas políticas de seus pais e consequente redefinições da vida cotidiana.

Inicialmente o pai, que é advogado, demonstra um conflito por ser de uma família espanhola que defendeu o ditador Franco e ele se afasta da Espanha. Porém, o cunhado é preso e ele se vê na condição de ter que abrigar a irmã e sobrinha, além de se sentir impulsionado a fazer alguma coisa, de ação e resistência. A mãe de Anna trabalha na revista Marie Claire, um periódico "feminino" francês. A partir desta movimentação da família, também faz a opção de romper com a alienação do seu trabalho burguês, e deixa a revista com o projeto de escrever e 
apoiar a causa feminista do direito ao aborto.

Desencadeada por estas escolhas políticas, há uma pequena revolução em curso na estrutura familiar, mudam-se completamente as condições materiais, da casa, das empregadas (que mudam constantemente, pois são sempre as exiladas de diversas nacionalidades, "abrigadas" pela família), ao tempo dedicado à família. Há também a presença de novos personagens na vida da família, que são os amigos "barbudos" e a luta contra o golpe militar no Chile, para onde os pais vão em viagem de apoio.

Tudo é narrado a partir do ponto de vista de Anna, que questiona, se revolta e assume o discurso "reacionário" de manutenção da ordem social burguesa que vivia em harmonia. Ou seja, o filme tem um componente de deslocamento a partir da criança de fazer a critica aos maniqueísmos naturalizados, dicotomizadamente, entre a esquerda e a direita no contexto do cenário político da luta de classes.

Mas, a perspectiva da criança não é utilitarista por parte da diretora, como recurso para fazer pensar sobre as condições dadas e as possibilidades de movimento que todos estamos inseridos em diversas situações. É um retrato sincero e singular de uma jovem artista que tem, no cinema, uma possibilidade de rememoração e expressão estética da sua própria história.

Julie Gravas é filha do diretor Constantin Costa Gravas, importante cineasta grego de filmes "politicos" (mesmo que ele enfatize que seus filmes não são políticos, são sobre a realidade, a sociedade em que vive), especialmente nos anos 1970 (como os clássicos Z de 1968 e Estado de Sítio, 1972). Em diversas entrevistas a cineasta destacou o quanto deste seu primeiro filme tem de inspiração sua própria experiência com a política.

E, vale ressaltar, a partir disto, que sua própria experiência com a política é de formação, inquietação e questionamento, sendo uma criança nos anos 1970. Ou seja, traz o ponto de vista da infância, mais do que fazer um filme sobre a política. É um documento histórico que aborda a questão da criança neste contexto como um novo sujeito social, que faz parte da história e constrói, a partir de suas condições concretas, suas primeiras reflexões sobre a política.

Outro aspecto que identifico neste movimento da diretora, é o de buscar uma linguagem autoral para tratar da "aparente" mesma temática do pai - ou da geração 
anterior a sua - que fazia cinema político a partir de suas escolhas estéticas. Essa busca ela frisa ser com mais humor e leveza para que possam, mais do que defender verdades, apontar os movimentos da construção de nossas convicções e escolhas. Estas, sim, sempre políticas.

Figura 5. Anna em três momentos com a família.
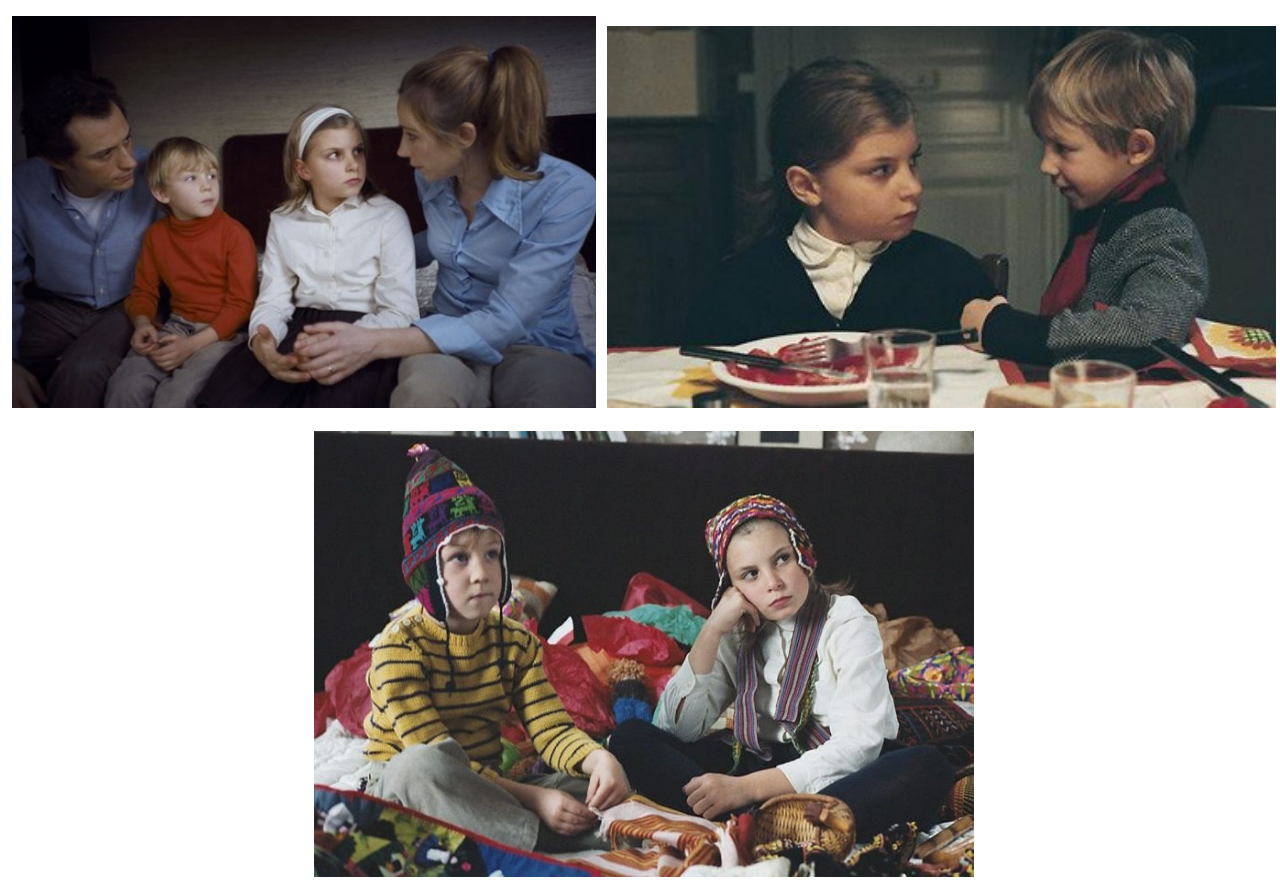

Fonte: Imagens da Tese de Doutorado: A estética da infância no cinema: poéticas e culturas infantis. SILVA, A. A. FE UNICAMP: Campinas, São Paulo. 2014, p. 93.

Em Machuca, Andres Wood, também ressalta sua experiência de rememoração no seu primeiro longa metragem de ficção. O filme se passa no Chile em 1973, quando ele tinha 8 anos, às vésperas do golpe militar que derrubou o governo de Salvador Allende e instalou a ditadura e o terror no país por quase 30 anos.

O filme narra o encontro de dois mundos, dos pobres e dos ricos no auge do processo socialista de Allende, pela ótica da infância no meio da luta de classes, protagonizada pelas crianças-personagens: Pedro Machuca e Gonzalo Infante, ambos com 11 anos.

Segundo o diretor,

A ideia parte de uma experiência pessoal que tive no começo da década de 70 em Santiago, em um colégio de classe média alta chilena, um colégio privado, que incorpora às turmas, de maneira significativa, alunos com 


\begin{abstract}
escassos recursos. Numa turma de 40 alunos, havia 15 de escassos recursos. Isso dura até exatamente depois do golpe (1973), quando o colégio sofre intervenção dos militares. Não é necessário conhecer a história do Chile para ver "Machuca", para entrar no filme e entendê-lo. Não é um filme hermético político. É político porque tem posição, mas é um filme mais social e mais da vida íntima daquelas crianças (SILVA, 2014, p. 94)
\end{abstract}

Diferentemente de Anna, Gonzalo, o "narrador" de Machuca se aproxima com curiosidade e solidariedade ao novo mundo que a presença das crianças pobres traz para o colégio de ricos e o mundo burguês que ele vive, permeado pela alienação e a traição da mãe ao pai, como das relações com a irmã e o namorado reacionário, assim como o pai distante, por fim ausente. Em diversas sequências, a narrativa se aproxima e desloca os personagens dos seus respectivos mundos determinados de classes sociais distintas, construindo uma zona de afeto e conforto entre os personagens, fora do mundo adulto perversamente dicotomizado, mas também os expondo aos estranhamentos recíprocos e às diferenças e desigualdades entre eles.

$\mathrm{Na}$ amizade, solidariedade e companheirismo que vão se instalando na relação entre os garotos, o ápice é a embriaguês dos dois na festa da irmã de Gonzalo e, em seguida, os beijos com leite condensado compartilhados entre os dois e Silvana (uma vizinha e amiga de Pedro Machuca. Ambos moram numa ocupação/favela nos confins da cidade, marcada pela presença das montanhas).

Além dos conflitos, tensões que indicam a iminência de uma tragédia anunciada - a ruptura desencadeada pelo golpe e a instauração da ditadura - no filme que é sustentado pelo ponto de vista de Gonzalo, se evidencia também a memória de Andrés Wood da classe média a espumar de raiva dos "favelados de merda" além da morte do Allende vista pela televisão, com a notícia da arma usada no seu suicídio ser um presente de Fidel Castro, e as medidas de intervenção e extrema violência tomada, a partir de então, no colégio e na ocupação/favela onde moram Machuca e Silvana.

A questão da estética da infância no cinema é uma invenção poética de um cinema autoral, marcado pela infância enquanto experiência e que tem em sua essência a intencionalidade de manipular e esculpir o tempo.

Figura 6. Machuca, como disse seu diretor, machuca. 

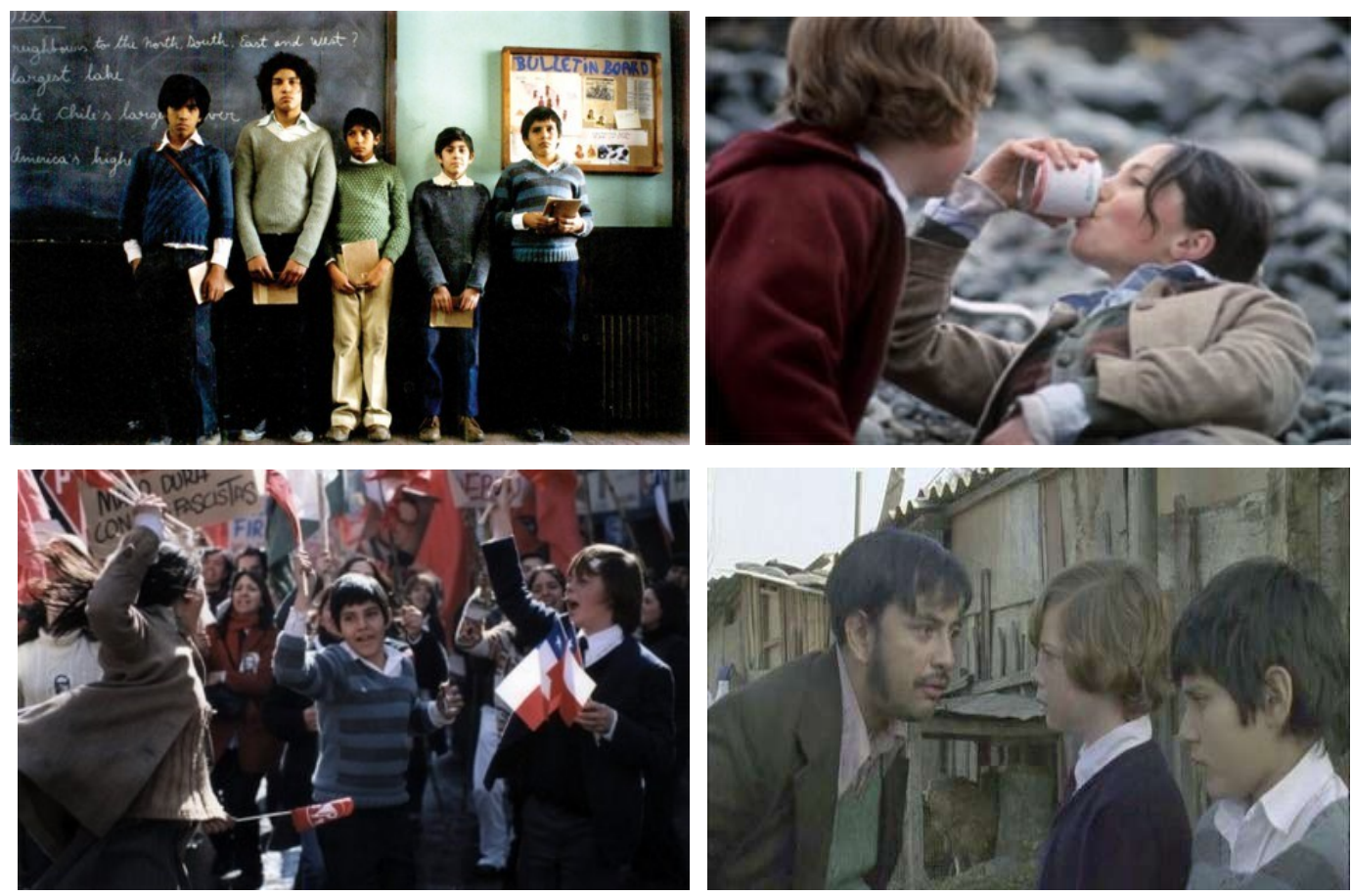

Fonte: Imagens da Tese de Doutorado: A estética da infância no cinema: poéticas e culturas infantis. SILVA, A. A. FE UNICAMP: Campinas, São Paulo. 2014, p. 95.

Na minha leitura e proposição, Machuca e A culpa é do Fidel, buscam de maneiras distintas viajar e incitar que também nós expectadores, viajemos no tempo. Com estéticas construídas a partir também da experiência infantil de seus respectivos diretores, apresentam poeticamente crianças sujeitas da história e, através delas, sentimos com o corpo todo os absurdos que permeiam a vida contemporânea, os processos e os movimentos que nos constituem, nos formam e deformam a todos, e nos convidam a revermos sonhos e utopias do passado, a fim de que, como Anna/Julie e Gonzalo/Andres, reinventemos o presente, compreendendo melhor o passado.

\section{A INFÂNCIA ROUBADA: AS CRIANÇAS NA DITADURA MILITAR BRASILEIRA}

Através dos livros O que resta da Ditadura (2010) e do clássico Brasil Nunca Mais (1985), pude ir delineando o movimento de encontro entre a memória pessoal e a coletiva que vivenciei durante todo o processo de pesquisa, em ambas publicações busquei referências em estudos que trazem a questão da infância. No primeiro, apresenta um texto muito especial de Janaína de Almeida Teles sobre Os 
familiares de mortos e desaparecidos políticos e a luta por verdade e justiça no Brasil, texto riquíssimo em informações históricas para compreendermos o drama de quem vivenciou ativamente este periodo da história brasileira. E, no Brasil nunca Mais, temos um pequeno capítulo sobre a tortura em crianças, mulheres e gestantes, com dados assustadores. Ambos trazem precioso relato histórico.

Maria Rita Kehl (2009) em seu livro O tempo e o cão: a atualidade das depressões $^{6}$, seguindo os rastros de Benjamim, dialoga com Freud, mas relaciona a melancolia com a depressão contemporânea, reforçando o projeto benjaminiano da potência do ato de rememorar e narrar o passado a fim de ressignificar o presente. Outro destaque é sobre essa potência do ato de rememorar que a autora ressalta na introdução ao livro, refletindo sobre a passagem do trauma de uma vivência pessoal para uma experiência coletiva. E, neste processo de "cura", as possíveis ressignificações vão sendo gradativamente atreladas a diversos fatores sociohistóricos que condicionam os traumas:

\begin{abstract}
Ao refletir sobre as condições de elaboração do trauma causado pelo Holocausto na sociedade alemã, Jeanne Marie Gagnebin retoma o conceito benjaminiano de rememoração. Trata-se de contrapor ao recalcamento da memória do trauma não um compromisso obsessivo com a má consciência que não cessa de evocar os sofrimentos passados, mas "uma memória ativa que transforma o presente ${ }^{7}$. Ou seja, a autora, que não é psicanalista e sim filósofa, pensa que uma "cura" para os sintomas sociais é possível. Ela pode se dar por meio de intervenções coletivas no espaço público, que reorganizem o campo simbólico de modo a incluir e ressignificar os restos deixados pelo evento traumático. (KEHL, 2009, p. 28).
\end{abstract}

Neste contexto coletivo da sociedade brasileira, reencontrar e "curar" os traumas do passado, cabe destacar a Lei N. 12.528, de 18 de novembro de 2011, que cria a Comissão Nacional da Verdade no âmbito da Casa Civil da Presidência da República. Sendo esta a expressão máxima deste movimento, após a Comissão da Anistia, os julgamentos e as indenizações reparatórias, busca-se neste momento construir uma memória coletiva, pública sobre a ditadura militar, a partir do enfrentamento das feridas abertas.

\footnotetext{
${ }^{6}$ Neste livro destaco dois capítulos que compõem a segunda parte de "O tempo e o cão: a atualidade das depressões", ambos em intensa interlocução com Walter Benjamim, trata-se de Temporalidade e experiência e A melancolia de Baudelaire e a lírica do choque.

7 Jeanne Marie Gagnebin, Após Auchwitz, em Lembrar escrever esquecer, São Paulo: Editora 34, 2006, p. 59.
} 
Na perspectiva de prever, ou de enfrentar a solidão do esquecimento e/ou do processo de impunidade perante as violências cometidas na ditadura militar, a Comissão da Verdade tem a tarefa de reconstruir a memória nacional do período, a partir da busca pelos rastros que não foram apagados ou silenciados pelo lento processo institucional das políticas públicas.

Neste movimento, cabe ressaltar os aspectos formativos de pesquisa, propostos a partir da criação de Grupos de Trabalho (GT), compostos por renomados pesquisadores envolvidos de alguma forma com pesquisas, participação e resistências políticas para realizar esta árdua tarefa de recolher os cacos, seguir os rastros e amalgamando os dados, as vozes, documentos esparsos, obscuros, a fim de construir e/ou criar uma memória coletiva, nacional para este período. Em especial, saliento o GT Ditadura e Gênero.

O livro $A$ aventura de contar-se: feminismos, escritas de si e invenções da subjetividade (2013), da professora e pesquisadora do Departamento de História do Instituto de Filosofia e Ciências Humanas (IFCH) da Unicamp, Margareth Rago, traz preciosas contribuições para este debate, tecendo as histórias, memórias, aventuras e desventuras de 7 mulheres, feministas e personagens históricas do Brasil contemporâneo.

Entre outras importantes reflexões, fantásticas personagens, destaquei o encontro especial com Maria Amélia de Almeida Teles - a Amelinha - e também com a sua irmã Criméia, ambas militantes do $\mathrm{PCdoB}$, sendo a última sobrevivente da Guerrilha do Araguaia. As duas foram presas políticas, torturadas com e juntos de seus filhos.

Entre "vivos-sobreviventes" e feridos, estas duas mulheres, feministas históricas do movimento de mulheres em São Paulo, estão na linha de frente da Comissão da Verdade e na produção do Seminário Verdade e Infância Roubada, realizado de 06 a 10 de maio de 2013, na Assembleia Legislativa do Estado.

O seminário colheu cerca de 50 depoimentos das crianças do passado envolvidas nos crimes cometidos na ditadura militar. Tratou de narrativas dos/as adultos/as traumatizados do presente? Na minha percepção não há como responder com precisão esta questão, pois é um complexo emaranhado de vidas nestas memórias. 
Os filhos de Amelinha também foram ouvidos no Seminário. Janaina de Almeida Teles e Edson de Almeida Teles, foram presos com os pais em 28/12/1972 e tinham 4 e 5 anos, respectivamente. Ambos também estão envolvidos com a Comissão da Verdade e os movimentos de luta por Justiça e reparação às vitimas da ditadura. Formaram-se na Faculdade de Filosofia, Letras e Ciências Humanas FFLCH da USP. Ela é historiadora e ele filósofo, Professor de Filosofia Política na UNIFESP. A repercussão do Seminário foi intensa na mídia. Uma emissora da TV aberta produziu uma série de reportagens que trazem estes depoimentos, as histórias destas crianças no passado e seus desdobramentos no presente.

Outra referência com imagens, narrativas e um caráter didático de apresentação histórica, é o livro Direito à Memória e à Verdade: história de meninas e meninos marcados pela Ditadura (2009) - uma publicação da Secretaria Especial dos Direitos Humanos -, explicitamente se evidencia uma intencionalidade pedagógica do Estado brasileiro. Parece ser um aparente movimento de amenizar e combater o esquecimento e a alienação coletiva sobre este período recente da história brasileira.

Figura 7. Imagens de divulgação do Seminário Verdade e Infância Roubada (maio de 2013). 


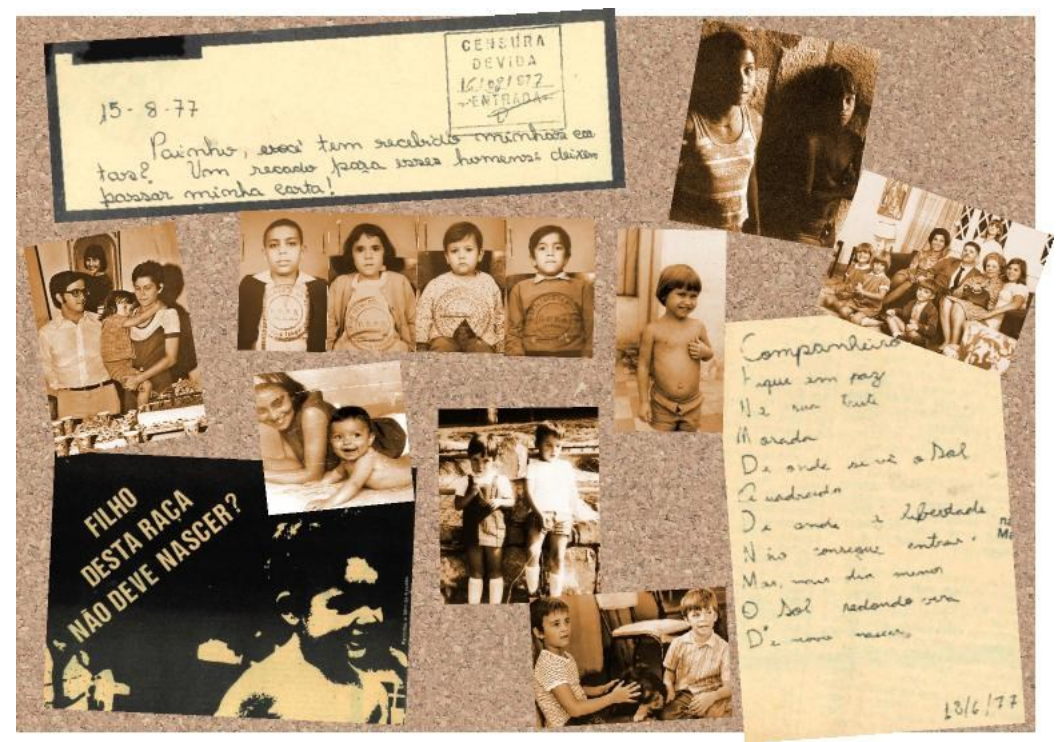

FoNTE: Imagens da Tese de Doutorado: A estética da infância no cinema: poéticas e culturas infantis. SILVA, A. A. FE UNICAMP: Campinas, São Paulo. 2014, p. 15.

\section{MEMÓRIA E POÉTICAS DA RESISTÊNCIA NO CINEMA LATINO-AMERICANO}

Para além dos filmes analisados e relacionados anteriormente - estes que apesar de serem considerados parte de uma cinematografia de arte mais autoral e com distribuição restrita, foram exibidos em salas de cinema comerciais - encontrei no processo da pesquisa, outras imagens e sons da memória alternativas, autorais, mais "marginais", excluídas da distribuição básica, producões de resistência na cinematografia contemporânea. Destaco, especialmente, os filmes de Albertina Carri, jovem cineasta argentina, presente nas últimas mostras de Cinema LatinoAmericano, em São Paulo.

Em 2010, na referida mostra paulistana, Albertina exibiu Restos (2010), um curta metragem de 8 minutos, que de maneira poética narra a descoberta de rolos de filmes "clandestinos", feitos por militantes de esquerda entre os anos 1960 e 1970 e encontrados recentemente. O Restos se insere dentro de um projeto audiovisual de 25 miradas (25 olhares), curtas-metragens de diversos autores, produzidos em razão da comemoração do bicentenário da independência argentina, encomendado pelo governo. Em 2013, apresentou na mesma mostra La Rabia (2012), um longametragem que fala de violência doméstica, das tumultuadas relações entre o mundo 
adulto e infantil, memória e resistência, através de múltiplas linguagens.

Albertina Carri despontou no cenário audiovisual latino-americano com o documentário Los Rubios (2003). Neste filme a diretora se coloca, explicitamente, como protagonista da narrativa, apresentando cenas dela e da sua equipe de filmagem, além da presença de uma atriz que se apresenta e a representa no filme, que é uma busca dos vestígios sobre sua mãe e seu pai, desaparecidos políticos, mortos pela repressão em seu país.

Segundo a historiadora Ana Maria Veiga, estudiosa das relações entre cinema, memória e resistências na América Latina,

\begin{abstract}
Carri leva consigo os traumas dessa perda violenta e da imaginação que remonta o tempo que eles passaram na prisão, sua tortura e depois morte. Em Los rubios, um filme que rompe com padrões narrativos, ela denuncia ao mesmo tempo os lapsos da memória e o mosaico que se pode formar com a contraposição de testemunhos sobre um mesmo evento e sobre as mesmas pessoas. A inserção de bonecos "playmobil" para reconstituir cenas de sua infância quebra com a dureza dos depoimentos, mas traz a dramaticidade da visão de uma criança sobre os acontecimentos. Lançado em 2003, seu filme nos mostra a atemporalidade da discussão sobre o tema das ditaduras e suas conseqüências, e a pertinência de se trazer este debate para o campo da história do tempo presente, embora com a problematização da questão central neste tipo de representação: a subjetividade (VEIGA, 2011, p. 02) ${ }^{8}$.
\end{abstract}

No filme Los rubios, Albertina documenta o processo de busca dos pais desaparecidos e de reconstrução de uma memória perdida, obstruída pela ditadura militar argentina, quando seus pais foram presos em 1977, quando ela contava com 3 anos de idade e suas irmãs eram um pouco maiores. O documentário é feito através de documentos esparsos da família, fotos, gravações do passado e do presente, e narra com sons e imagens múltiplas uma poética autoral dilacerante, inclusive ficcionando sua própria experiência de vida.

Albertina Carri transita do cinema documentário para o cinema de ficção, apresentando experiências de um cinema de poesia, como defendeu o cineasta russo Andrei Tarkovski, "poesia como visão de mundo" (Tarkovski, 2010). É uma artista transgressora de gêneros, pois seus filmes são híbridos, mesclam imagens de arquivo, diversas técnicas de animação e propõem uma abertura para infinitas possibilidades estéticas, para sua poética em construção. 
Figura 8. Imagens da produção documental/ficcional LOS RUBIOS (2003).
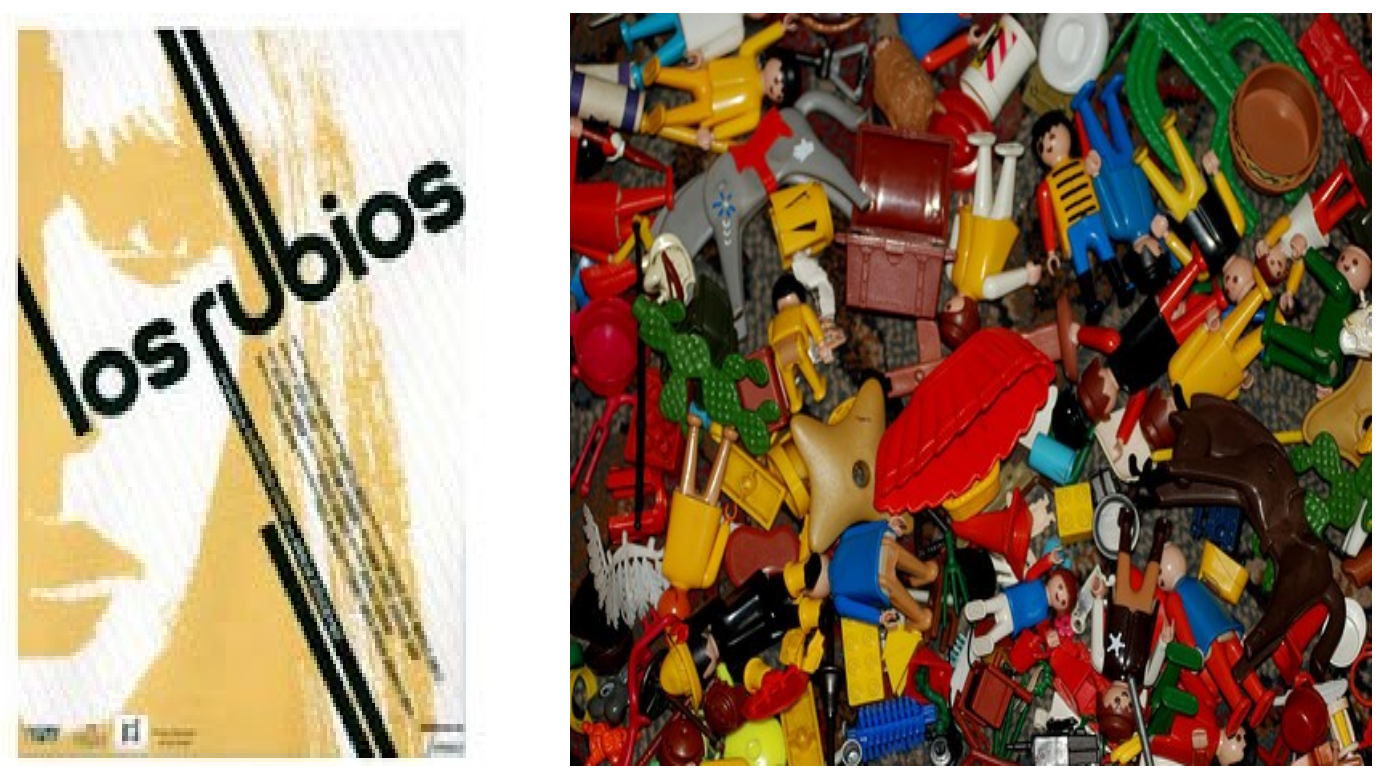

Fonte: Imagens da Tese de Doutorado: A estética da infância no cinema: poéticas e culturas infantis. SILVA, A. A. FE UNICAMP: Campinas, São Paulo. 2014, p. 167.

\section{CONSIDERAÇÕES FINAIS}

As relações entre cinema, infância e educação têm, na indissociabilidade da arte com a política, uma chave para pensarmos nos intermitentes desafios de politização da arte, contra a estetização da política. Isso, conforme nos alertou Walter Benjamim (1985) em seu precioso e pertinente ensaio A obra de arte na era de sua reprodutibilidade técnica, escrito nos anos 1930, entre guerras, pleno das ressonâncias das tragédias do século e ainda uma referência crítica fundamental para a compreensão da arte, em destaque a arte cinematográfica e sua função social fundada na práxis política.

Nesta perspectiva, defendi o cinema na interface com a educação, em sua dimensão de artefato cultural, imbricado nas tramas da arte e da política, um potente documento histórico que, em seus movimentos e deslocamentos do passado no presente, nos inquieta e nos provoca a pensarmos na nossa responsabilidade coletiva e histórica sobre e com a infância que temos, e a que queremos.

Problematizando as relações entre a infância no contexto das lutas que 


\section{Atos de Pesquisa em Educação - ISSN 1809-0354}

Blumenau, v. 10, n.3, p.690-710, set./dez. 2015

DOI: http://dx.doi.org/10.7867/1809-0354.2015v10n3p690-710

marcaram a história do século XX, evidenciamos a intencionalidade de construirmos coletivamente novas possibilidades de compreensão das crianças na história do tempo presente. Com foco na importância fundamental dos movimentos sociais que lutam pelos direitos humanos, e no contexto de luta por verdade e justiça pelos crimes cometidos nas ditaduras militares que assolaram o Brasil e outros países da América Latina, buscamos evidenciar as formas como a infância e as crianças vêm sendo vistas, ouvidas e consideradas neste processo de construção de outras memórias sobre a nossa história.

O cinema, em sua interlocução com a infância - ambos experiências em suas dimensões históricas - também pode ser compreendido como um instrumento de pesquisa e criação na educação. Assim, vai-se configurando em uma preciosa possibilidade de educação do sensível nos processos de formação de professores/as que estão inseridos/as nos contextos institucionais de educação, uma vez que possibilitam novas apreensões e percepções sobre os gestos infantis, suas transgressões, criações e resistências em movimento.

\section{ADRIANA A. SILVA}

Doutora em Educação pela FE/Unicamp. Pesquisadora do GEPEDISC - Culturas Infantis da FE Unicamp. Professora efetiva da Rede Municipal de Ensino de Florianópolis/SC. Atua na formação continuada na Rede Municipais de Ensino de São José/SC.

\section{REFERÊNCIAS}

ARNS, P. E. (org.) Brasil nunca mais. São Paulo: Editora Vozes, 1985.

ALMEIDA, M. J. Cinema Arte da Memória. Campinas: Autores Associados, 1999.

ALMEIDA, M. J. As idades, o tempo. Campinas: Pro-Posições. vol. 15, n. 1 (43). jan/abr 2004, p. 39-62.

BENJAMIN, W. Magia e Técnica, Arte e Política: ensaios sobre literatura e história da cultura - Obras escolhidas, Volume I. São Paulo: Brasiliense, 1985.

BRASIL. PRESIDÊNCIA DA REPÚBLICA. Lei No 12.528, de 18 de novembro de 2011. Institui a Comissão Nacional da Verdade no âmbito da Casa Civil da Presidência da República. Brasília - DF, 2011. 
GAGNEBIN, J. M. Lembrar escrever esquecer. São Paulo: Editora 34, 2006, p. 59.

GAGNEBIN, J. M. História e narração em Walter Benjamim. São Paulo: Editora Perspectiva, 2004.

JAMESON, F. As marcas do visível. Rio de Janeiro: Graal, 1995.

KEHL, M. R. O tempo e o cão: a atualidade das depressões. São Paulo: Boitempo, 2009.

PASOLINI, P. P. Genariello: a linguagem pedagógica das coisas. In LAHUD, M. (org.) Os jovens infelizes: antologia de ensaios corsários. São Paulo, Editora Brasiliense, 1990, p. 125-136.

RANCIĖRE, J. A partilha do sensivel: estética e política. São Paulo: Editora 34, 2005

RAGO, M. A aventura de contar-se: feminismo, escrita de si e invenções da subjetividade. Campinas, SP: Editora da Unicamp, 2013.

RIDENTI, M. O fantasma da Revolução Brasileira. São Paulo: Editora UNESP, 2010.

SILVA, A. A. A Poética do Cotidiano com Clarice Lispector: emergindo imagens. 2008. Dissertação (Mestrado em Multimeios: Cinema e Vídeo) - Universidade Estadual de Campinas (Instituto de Artes, UNICAMP), Campinas.

SILVA, A. A. A Estética da Infância no Cinema: poéticas e culturas infantis. 2014. Tese (Doutorado em Educação) - Universidade Estadual de Campinas (Faculdade de Educação, UNICAMP), Campinas.

TARKOVSKI, A. Esculpir o Tempo. São Paulo: Martins Fontes, 2010.

TELES, E.; SAFATLE, V. O que resta da ditadura. São Paulo: Botempo, 2009.

TELES, M. A. A. Breve História do feminismo no Brasil. São Paulo: Editora Brasiliense, 1999.

TELES, A.; LEITE, R. S. C. Da guerrilha à imprensa feminista: a construção do feminismo pós-luta armada no Brasil (1975-1980). São Paulo: Intermeios, 2013. (Coleção Entregêneros).

TEIXEIRA, I. A. C.; LARROSA, J.; MIGUEL, J. (orgs). A Infância vai ao cinema. Belo Horizonte, Editora Autêntica, 2006.

VEIGA, A. M. Cineastas brasileiras em tempos de ditadura: cruzamentos, fugas, especificidades. 2013. Tese (Doutorado em História) Departamento de Historia da Universidade Federal de Santa Catarina. Florianópolis.

XAVIER, I. A experiência do Cinema. Rio de Janeiro. Editora Graal, 1983.

A CULPA É DO FIDEL, Direção: Julie Gavras, Roteiro: Arnaud Cathrine, Domitilla 
Calamai, Julie Gavras, Produção: Sylvie Danton, Fotografia: Nathalie Durand, Trilha Sonora: Armand Amar, Duração: 99 min., Ano: 2006, País: França / Itália, Cor: Colorido, Classificação: 14 anos.

A HISTÓRIA OFICIAL, Direção: Luis Puenzo, Roteiro: Aída Bortnik, Luis Puenzo, Produção: Marcelo Piñeyro, Fotografia: Félix Monti, Trilha Sonora: Atilio Stampone, Duração: 112 min, Ano: 1985, País: Argentina, Cor: Colorido

A INFÂNCIA CLANDESTINA, Diretor: Benjamim Ávila, Roteiro: Benjamín Ávila, Marcelo Müller, Produção: Benjamín Ávila, Luis Puenzo, Fotografia: Iván Gierasinchuk, Trilha Sonora: Marta Roca Alonso, Pedro Onetto, Duração: 112 min., Ano: 2011, País: Argentina / Brasil / Espanha, Cor: Colorido, (Brasil), Distribuidora: Imovision, Classificação: 14 anos.

KAMTCHAKA, Direção: Marcelo Piñeyro, Roteiro: Marcelo Figueras, Marcelo Piñeyro, Produção: Francisco Ramos, Óscar Kramer, Pablo Bossi, Fotografia: Alfredo F. Mayo, Trilha Sonora: Bingen Mendizábal, Duração: 105 min., Ano: 2002, País: Argentina / Espanha, Cor: Colorido, Classificação: Livre

LA RABIA, Direção: Albertina Carri, Roteiro: Albertina Carri, Produção: Producción Pablo Trapero, Martina Gusman , Agustina Llambi-Campbell, Daniel Agustin Iniguez, Fotografia: Sol Lopatín, Duração: 89 min., Ano: 2008, País: Argentina, Cor: Colorido

LOS RUBIOS, Direção: Albertina Carri, Roteiro: Albertina Carri, Produção: Pablo Wisznia e Barry Ellsworth, Fotografia: Catalina Fernández,Trilha Sonora: Gonzalo Córdoba, Duração: 89 min., Ano: 2003, País: Argentina, Cor: Colorido.

MACHUCA, Direção: Andrés Wood, Roteiro: Andrés Wood, Mamoun Hassan, Roberto Brodsky, Produção: Andrés Wood, Gerardo Herrero, Mamoun Hassan, Fotografia: Miguel Ioann Littin Menz, Trilha Sonora: José Miguel Tobar, Miguel Miranda, Duração: 120 min, Ano: 2004, País: Chile / Espanha / Reino Unido, Cor: Colorido

O DIA EM QUE EU NÃO NASCI, Direção: Florian Micoud Cossen, Roteiro: Elena von Saucken, Florian Micoud Cossen, Produção: Birgit Metz, Claudia Gladziejewski, Fabian Maubach, Jochen Laube, Fotografia: Matthias Fleischer, Trilha Sonora: Matthias Klein, Duração: 95 min., Ano: 2010, País: Alemanha / Argentina, Cor: Colorido, Distribuidora: Serendip Filmes, Classificação: 12 anos

O ANO EM QUE MEUS PAIS SAÍRAM DE FÉRIAS, Direção: Cao Hamburger, Roteiro: Anna Muylaert, Bráulio Mantovani, Cao Hamburger, Cláudio Galperin Fotografia: Adriano Goldman, Trilha Sonora: Beto Villares, Duração: 106 min, Ano: 2006, País: Brasil, Cor: Colorido, Estúdio: Gullane Filmes, Classificação: 10 anos.

RESTOS, Direção: Albertina Carri, Roteiro: Albertina Carri, Produção: Albertina Carri e Barry Ellsworth, Fotografia: Catalina Fernández, Duração: 89 min., Ano: 2010, País: Argentina, Cor: Colorido. 